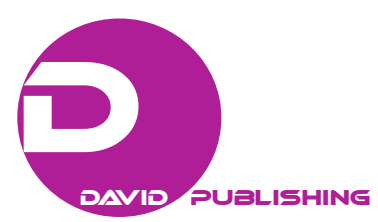

\title{
Project-Based Learning as 21st Century Teaching Approach: A Study in Nepalese Private Schools
}

\author{
Dhundi Raj Giri \\ Kathmandu University, Lalitpur, Nepal; \\ Center for Activity Based Instruction (ABI), Lalitpur, Nepal
}

\begin{abstract}
Learners learn the best when they are engaged in learning by doing. In order to cope with the 21st century problems, learners need to be prepared with 21st century skills and project-based learning (PBL) can be one of the best 21st century teaching approaches. This article focuses on PBL, 21st century skills, the 21st century learners, and 21st century schools as workplace, teachers' perceptions and practices of PBL, learners' motivation and engagement in PBL, challenges and learning enhancement in Nepal as English as a foreign language (EFL) context. Likewise, the author has also discussed about the research questions, data collection, data analysis, and implication of the study. This research article can give insightful information about PBL in EFL context in Nepal.
\end{abstract}

Keywords: project-based learning (PBL), 21st century skills, school as workplace, motivation, prolonged engagement, global issues, 21st century knowledge and skill

\section{Introduction}

Tell me and I forget. Show me and I remember. Involve me and I understand.

-A Chinese proverb.

As the proverb above goes, it is a widely accepted idea that learners learn better when they are engaged in real life situations or experiential learning. So, the learners' engagement in the teaching learning activities plays a vital role in their learning achievement. More engagement of the students results in the higher level of achievement. However, teaching learning practice in Nepalese context is quite contrary, where teachers sweat in the classroom teaching and students remain as passive listeners following orders and instructions of the teacher. As Defelice (1996) stated, "Teaching in monolingual/monocultural, and non-English speaking environment at a time can be frustrating” (p. 43). Everything gets changed over the certain span of time. Today's children are not going to learn as their parents did. Even the teaching learning methods we practiced in the past may not fulfill the needs and demands of 21st century learners. Highet (2008) expressed that methods in any country alter every generation or so, as the structure and ideals of society alter. To meet the ever-changing needs of students in the modern world, educators need to have forward thinking and change the traditional way of thinking in order to incorporate the new ways of learning. Karn (2007) also mentioned that language teaching in general and English language teaching (ELT) in particular have tremendously changed over the centuries. In this dynamic world, in order to tackle the challenges of the new era in learners, project-based learning (PBL) can be an effective method in enhancing the learners' learning achievement in English as a foreign language (EFL) context.

Dhundi Raj Giri, M.Phil., scholar in English Language Education (ELE), School of Education, Kathmandu University; Promotion and Development director, Center for Activity Based Instruction (ABI). 


\section{Project-Based Learning (PBL)}

PBL is a practical and research oriented method of teaching in which learners get prolonged engagement in creating, building, and testing what they have created or designed in collaboration with other learners, both inside and outside the classroom. According to Stripling, Lovett, and Macko (2009), "Project-based learning is the instructional strategy of empowering learners to pursue content knowledge on their own and demonstrate their new understandings through a variety of presentation modes." Students are engaged in different stages of activities for the task completion in which they go through in-depth investigation through interview, observation, lab, and library research accumulating the required information. Blank (1997), Dickinson et al. (1998), and Harwell's (1997) project-based instruction is an authentic instructional model or strategy in which students plan, implement, and evaluate projects that have real-world applications beyond the classroom (as cited in Brewster \& Fager, 2000, p. 4). As project-based learning is more focused on students' activities, they are involved in the planning, designing, and implementing the project in real life situation in collaboration with co-learners and the teacher who provides scaffolding in their learning. Moreover, "Learning activities are interdisciplinary, long term, and student-centered, rather than short and isolated lessons” (Challenge, 2000; Multimedia Project, 1999; as cited in Brewster \& Fager, 2002, p. 4). From very beginning to the end of the project work, students are engaged in variety of activities-discussion on the topic, its scope, task division, working with the community people in course of field study, preparing the draft, editing, and presenting the project details in front of the classroom. So, students are engaged in such a meaningful way, they construct the knowledge on their own, rather than just depend on the readymade knowledge, prescribed by the teacher or in textbook. Thus, students' engagement in real life issues and collaborative approach can be essential for developing variety of skills, communication and presentation skills, critical thinking, creativity, collaboration, research and technical skills, and management skills, similar to Pearlman (2006) who emphasized on the 21st century skills to cope with 21st century problems and issues. Therefore, the learners need to be equipped with these 21st century knowledge and skills. Moreover, it is, as Grant (2002) said, "learner-centered strategy that affords learners the opportunity for in-depth investigations of worthy topics and the learners are more autonomous” (p. 1). Therefore, student-centered strategy and varieties of activities integrated with real life problems and issues in PBL play a vital role in enhancing the learners' achievements.

However, the present textbook driven teacher-centered traditional teaching learning practices has been found unable to guarantee these 21st century skills in the learners. In such scenario, it is necessary to foster these skills in the young generation. Otherwise, they will be left far behind. As a result, our young generation will have to struggle to be the part of the globalized world. As Pearlman (2006) further said, "Societies need citizens who are smarter, more creative, and more capable of leading, managing, collaborating, and networking with productive people around the world.” Such multi-dynamic work force can be prepared only though providing them abundance learning opportunities in real life situation, engaging them in varieties of projects, where they work together with other fellow learners as per their needs and demands. So, PBL, in such situation, can serve as an authentic strategy for enriching the 21st century skills in the learners.

\section{School as Workplace for 21st Century Learners}

As students spend around 13 years of time in school from pre-school to secondary level (in Nepalese context), they bear a big responsibility to prepare the learners for their life, fostering the knowledge and skills 
required to survive and thrive in the 21st century global market. However, the traditional schools are not found to be as much productive as they should be, because not only the school graduates, but also most of the university graduates are found lacking the required knowledge and skills: communication, creativity, innovation, research and technical skills, and so on, to perform their responsibilities efficiently in their day to day life. It is because learners get rare or no opportunity for independent learning environment, engaging them in creativity and critical thinking, and working in collaboration with their team. Schools, at present, consist of unmanageable number of students in congested classrooms, and teach through one way lecture method where students have to listen to their teacher passively. So, this kind of teaching learning practices can hardly bring the expected result. Therefore, it is necessary to restructure our schools or classrooms as workplace where students can learn independently, working in collaboration, using not only the paper, pens, and textbooks, but also varieties of technological tools and sufficient learning resources.

In such situation, PBL can be a milestone for preparing students as global citizens with knowledge and skills to tackle the problems and issues in 21st century global market. As Pearlman (2006) said, students should be provided with working environment involving computers, group work, planning, presentations, team teaching, etc.. Therefore, they are engaged in creating building and testing what they have made under the guidance of their teacher through scaffolding. Creating the efficient learning environment in the classroom is necessary to change the classroom situation as a workplace, where as Grant (2002) expressed that the learners are more autonomous, as they construct personally meaningful artifacts that are representations of their learning (p. 1). Therefore, it is necessary to create the collaborative and interactive learning environment where the learners can construct new knowledge and skills through collaborative approach. The classroom should be like family environment where the students try to support each other for a new adventure full of all kinds of new experiences, through which they can develop new relationships (Broz, 1999, p. 161).

\section{1st Century Learners}

The 21st century learners are smarter, dynamic, and more informed who are flooded with abundant information and options, due to the advancement of variety of social media, and have better access to limitless sources of information (Perlman, 2010). Due to excessive use of internet and computer technology, learners have access to vast resources in their finger tips, so they can find whatever, wherever, and whenever. Therefore, learning can take place anywhere anytime. Despite such opportunities, they also have greater challenges to adjust in this 21st century globalization. Moreover, the traditional Nepalese teaching learning practice is not likely to fulfill the needs of time, since it is also difficult to develop the required knowledge and skills in the learners needed to overcome the 21st century global challenges. The author thinks it is the time to rethink about the existing teaching learning practices and what sort of human resources you need to produce to face the challenges in the uncertain future. In this context, learners need to have prolonged engagement in variety of meaningful multidisciplinary hands-on activities, creating a self-directed and independent learning environment as per their needs and interests in collaborative approach. The smarter and better communicators, collaborators, and performers can be produced for the workplace and society of the future (Pearlman, 2006).

\section{Data Collection}

In order to understand the teachers' perceptions and practices of PBL in Nepal and its scope in EFL context, the study used a purposive sampling method to select research participants. We selected five in-service English language teachers in EFL context. We used interview and participant observation as research tools to collect the 
necessary data required for this purposed study. After the selection of the research participants, the author interviewed them dealing with the research questions. It was a semi-structured interview. The author also led the discussion on the issues that had occurred in the course of interview, besides the major research questions, based on their experience and the issues they had raised. Besides interview, we also observed some of their classroom practices regarding the PBL to capture the actual practices, so that we could collect the rich data.

\section{Research Questions}

In order to assemble the data required for the purposed study, the author designed "How does PBL contribute to enhancing 21st century skills in the learners in EFL context?" as the major research question along with other subsidiary questions:

1. What is the teachers' understanding and practices of PBL in EFL context?

2. How is the learners' motivation and engagement in PBL in EFL context?

3. How does PBL enhance knowledge and skills in learners?

4. What are the opportunities and challenges in implementing PBL in Nepal as EFL context?

\section{Data Analysis}

Here, the author has analyzed the data using interview and observation as the research tools. Based on the data, the author has generated altogether four themes to answer the research questions.

\section{Theme 1: Teachers' Perception and Practices on PBL}

At present, PBL has been a hot cake in different schools and colleges in Nepal. So, it is found that most of the schools have warmly welcomed this approach and accepted it as an integral part of academic activities, though most of the project works are limited for the sake of project work without having as much learning as it should be. However, it could be taken as a positive sign that new methods of teaching and approaches have been introduced in traditional Nepalese educational practices.

In response to the question regarding the perception towards PBL, Tirth, similar to Grant (2002) stated, "It is a quite new, democratic, scientific, useful, research-based, and practical kind of learning where students learn working in the real life situations.” In this sense, PBL is a learner-centered on the learners and affords learners the opportunity for in-depth investigations of worthy topics. The learners are more autonomous, as they construct personally meaningful artifacts that are representations of their learning. Moreover, PBL is a student-centered, research based, practical, and innovative kind of learning where they get prolonged engagement on the project works. They are encouraged to consult wide variety of resources, explore the huge number of information relevant to their topic that leads their learning to the in-depth investigation and developing their in-depth knowledge regarding the topic of study.

Adding to it, Rameshwor (2016), in response to the author's question, stated, “As PBL is innovative and practical kind of learning, it is good for preparing the learners for life, rather than just storing the theoretical knowledge in their mind." In the observation to the project work under the topic-social problems existing in the local area, the author found students engaging in the field of in their local community, interviewing different people, making notes, taking video clips, and taking photographs along with their classroom discussion and Internet surfing for further information in collaborative approach. This way they are encouraged to consult wide resources of information, carefully and critically interpret and analyze the data for finding the possible solution of the problems in collaborative approach. Actually, it helps them to be prepared for life rather than theoretical knowledge. 
Similarly, following the idea of Pearlman (2006), Tikaram focused on the benefits of PBL for enhancing different life skills, Rameshwor claimed,

PBL deals with students' creativity and suitable to new generation. It helps them to develop communication and collaboration skills, creativity and critical thinking skills, management and leadership skills, since students are actively engaged in each and every activity as part of their project works. So, the learners can develop the level of confidence and capability of facing the everyday challenges.

The 21st century new generation is and should be different from their forefathers, not only in terms of their needs and interests, but also in capabilities to face the challenges for the uncertain future. Therefore, it is necessary to equip them with different variety of life skills and knowledge, preparing them for life and making them able to face the numerous challenges that may occur in the uncertain future.

Sunil (2016), one of the participants, in response to the author's question, shared his view on PBL highlighting the importance of PBL in the field of academia. He said,

Unlike the traditional teacher-centered method, project-based learning is an effective, need-based technique in this 21st century. Students are taught by involving them in the real life issues based on their needs and desires using technologies in teaching learning practices. It is one of the techniques which make learning student-centered where students involve themselves in the learning process.

Taking the reference of Sunil, PBL is quite different from the teacher-centered, textbook-limited, and rote learning. It is one of the effective methods of teaching, in terms of its practicality, innovation, students' engagement, and the use of wide resources of learning where students are actively engaged in the learning by doing process on hands on activities based on their needs, interest, and relevant to their topic. Moreover, the use of technologies, field visits, and working with the community people are integral parts of their study which help them to develop 21st century life skills as mentioned earlier. In this regard, Stripling, Lovett, and Macko (2009) can be appropriate who stated that PBL is the instructional strategy of empowering learners to pursue content knowledge on their own and demonstrate their new understandings through a variety of presentation modes. So, using PBL is taking the learners into the world of experiences through their direct involvement in the real life issues to pursue new knowledge on their own.

Underlining the collaboration and cooperation, Surya (2016), another participant, stated, "It is effective and helpful for developing co-operation and collaboration among the group members, since everyone is involved in the real life situations, taking interview, making notes, recording video, and observing for the successful completion of the project work." Actually, cooperation and collaboration are essential components of 21st century learning. So, it is necessary to equip the learners with these knowledge and skills to cope in the globe market, working with the people having different socio-cultural backgrounds, promoting socio-cultural harmony, and respecting and equally valuing each other with their socio-cultural differences.

\section{Theme 2: Learners' Engagement and Motivation in PBL}

Creating conducive environment is essential for motivating learners and engaging them in the different activities for higher level of achievement. Unlike the congested and crowded classrooms with little or no resources and teacher-centered one size fits all methods of teaching are almost boring and outdated today. Therefore, motivating the learners and engaging them in meaningful learning has been a great challenge for the teachers. In such frustrating situation, the proper use of PBL can be a great achievement in the field of academia. Actually, motivation is the act or process of providing motive that causes a person to take action 
(Shanks, 2007, p. 24) and it can be both intrinsic and extrinsic. In response to the question to students' engagement and motivation regarding to PBL, Rameshwor similar to the idea of teaching English as a foreign language (TEFL) (2014) shared his strategy of using PBL among his students. He said,

First of all, I identify the topic based on the learners' needs and interests relevant to the curriculum. Then, students are divided into different groups and task is divided among the group members. I provide them with support in each and every step as they need till the final product or outcome is produced.

From the above statement, it can be understood that collaborative approach and working in the real life situations are essential for motivating the students for learning. "Motivation is the inner power or energy that pushes one toward performing a certain action” (Ball, 2012, p. 4). And both kinds of motivations, intrinsic and extrinsic, have been used in the above process. Such as working in collaboration, visiting field, interviewing, observing the real events in the real life situation, and communicating with the community people can be extrinsic motivation, whereas developing the certain knowledge and skills-communication, collaboration, and critical thinking can be the intrinsic motivation for the learners just like. As a result, students feel that they have a stake in their own learning which increases their learning and performance, and Sunil, supporting the idea of Tikaram, also expressed the similar line of thought.

In addition, in the course of the naturalistic participant observation, the author found the most of the learners being excited to participant in the each and every step of project based learning. All the learners were engaged in their project work during/out of the school time. They were engaged in creating building and testing what they have made under the guidance of their teacher through scaffolding. As a result, the successful completion of the project work was possible. So, for the successful completion of the project work, students should be provided with the working environment, involving them in varieties of activities on computers, planning, presentations, and team teaching in collaborative approach. By getting helping hand of their teacher, the author found each member from each group actively took part in each step up to the classroom presentation of their project work with full confidence and excitement. They had covered almost all the areas of their project work. Students' engagement was far better than usual classroom teaching, since each and every individual student was enthusiastically engaged in the project work with high level of motivation, as they were provided with the full autonomy. As project works are long term, interdisciplinary, student-centered, and integrated with real-world issues and practices, learners are engaged in meaningful learning (Shanks, 2007, p. 24), moving beyond the rote learning and memorization. As a result, students' motivation in learning increases.

Adding to the idea of Tikaram and Sunil, Surya shared his opinion focusing on the different opportunities the learners get in PBL. He said,

They have several opportunities while working on PBL, such as involving in the real life issues and real life situations and communicating with the community people. They also get opportunities to have real life experiences, develop communication, technological skills, management skills, and leadership as they differently visit the different organizations in the community communicating with the real experts rather than just depending on the teachers' lectures and textbook.

Actually, it is human nature that everyone wants to get new experience with fun which is possible through collaborative approach. In PBL, students get more choices to their voice and teachers are the guide on their side rather than sage on the stage. So, students' motivation is high in PBL, since more the educators give students choice, control, challenge, and collaborative opportunities, the more motivation and engagement are likely to 
rise (Toshalis \& Nakkula, 2012, p. 27). Thus, the real learning takes place. Comparing the traditional classroom, Tirth further stated that the traditional classroom is like one way traffic, since teacher is active and students are passive, whereas in PBL, teacher provides them with instruction for the work, planning and facilitating them in the different stages of project work. In this sense, students' choice to their voice and continuous support from the teacher from beginning to the successful completion of the project is another factor for motivating the students for prolonged engagement in the different stages of the project work.

\section{Theme 3: PBL and Enhancement of Knowledge and Skills}

Enhancement of knowledge and skills is inevitable for successful learning. It is necessary to equip learners with both knowledge and skills to help them to survive and thrive in the 21st century global context. In the course of designing and implementing several project works, PBL has been found to be one of the effective and best approaches for 21st century learning. Tirth, regarding this issue, shared his opinion similar to the idea of Meganathan (2011). He said that when learners work together on a particular idea/topic, they collect information, ideas, observe language being used, use language in real life situations, exchange views, debate on ideas, write the ideas into a report, edit their writing, and produce the report in a suitable form. Actually, unlike the traditional classroom, PBL provides several opportunities for the learners to work in team on real life issues, working with the real experts, rather than depending only on their teachers. In addition, going beyond the textbook and the classroom contents to memorize, learners are exposed with several aspects of the topic of their study, and encouraged to critically observe every details. The classroom content is connected with the real life issues and students have fun learning while working in their own community in collaborating with other co-learners in new situation with new experiences.

Supporting the idea of Tirth, Rameshwor shared his opinion that as project work is interdisciplinary in nature, students get opportunity to develop in-depth investigation and various skills while going through various project works. In the course of the naturalistic participant observation, the author found that some of the project works integrated with two or more subjects-English and social studies. For instance, one of the project works was designed focusing on the content from social studies under the topic social problems existing in the local area and it was to be presented in the form of report writing. From this project work, it can be understood that students, working on the various stages of the project work, can develop the in-depth information about the concerned topic. Tikaram also shared his view in the same line of thought. He said that group work is the very essential part of PBL. Students get opportunity to work in team that helps them to develop the interactive, communicative, and collaborative skills at the same time. As there is active learning in PBL, the learners are encouraged for the variety of research-based activities that develop their problem solving skills. Sunil, adding on it, said, "As project work is an integration of different things, it deals with different aspects of the topic." He further said that it develops students' level of confidence, critical thinking, and social skills, working inside and outside the classroom situation. Actually, this idea of PBL is really noteworthy, since group collaboration lies in the heart of project work which provides them an ample opportunity to work both inside and outside the classroom.

The learners are engaged in varieties of works according to the nature of project works that enable them to develop the most essential skills, like collaborative skills, time management skill, critical thinking, technical skills, research and social skills, and so on, which are known as 21st century skills. In the same way, as they get opportunity to work outside the classroom in team according to their needs and interests, it gives them a sense of excitement to undergo through the different stages of project work. It provides the learners with higher level 
of learning outcome. Adding to it, Surya said that PBL can be very useful to get the real life experience outside the classroom. Working outside the classroom is another essential feature of PBL, especially in real life experience, so that learners can develop their critical thinking and problem solving skills. Working in/outside the classroom and visiting the field, PBL provides an opportunity, as Chard (2014) shared her opinion that project learning is in-depth learning in which children can take some ownership of their work and through which they have choices that they can make but choices that are designed together by the child and the teacher, so they are not entirely whatever the child wants to do, but choices from among alternatives. To make it short, PBL helps students to seek the answers of different questions - what, why, how, and when, for example, to satisfy the curiosity and expectations of the learners regarding the topic their study.

\section{Theme 4: Challenges of PBL in Nepalese Context}

From the above discussion, PBL has been found to be an effective and demanding approach of teaching for the 21st century learners. However, its successful implementation may differ in different contexts. Actually, for the successful implementation of PBL, it requires spacious rooms with adequate resources, modern technologies, and trained and experienced teachers to guide and motivate the learners for in-depth investigation of the topic of study. In the course of interview, in response to the question, Tirth expressed, "No skilled manpower is available to implement PBL in the classroom in Nepalese context.” The author agrees with his idea in a sense that the concept of PBL is new in Nepalese context, so only a few schools have used it, actually not as the part of main teaching method rather as extracurricular activities. Besides, it is the ground reality that Nepalese teaching learning system is still dominated by textbook-limited and teacher-centered teaching. Therefore, it is hard to find skilled and trained teachers with sufficient knowledge and skills to successfully implement it. Further, he said that in most of the cases, the textbook teaching is regarded as curriculum. So, as most of the teachers focused on teaching and completing the contents, they hardly manage extra time for conducting the project works and have prolonged engagement of the learners. Therefore, when anybody talks about conducting project works, most of the teachers have the common voice, "It is not possible in our context." In such case, successful application of PBL can be challenging.

Dealing with the challenges of using PBL in Nepalese context, Rameshwor also shared his opinion regarding the matter of time management. He said, "Nepalese teaching learning practice is based on fixed textbooks which teachers must complete within the allocated time frame. So, teachers cannot go beyond the textbook for such project work, even though learning outcomes is higher.” In the same way, supporting Rameshwor and unlike idea of Bass (2014) about the role of teacher, Tikaram quite contrarily said, "We teachers are the sage on the stage, but not the guide on the side of the students which is the great hindrance to implement PBL." Successful implementation of PBL in classroom, as the author has already mentioned above, teachers' role is important. However, the trained and skilled human resources who can properly design and implement the project works relevant to the learners' needs and interests, ability to control and guide the learners, and motive the learners for independent learning, is lacking in Nepalese context. The existing teachers who are habituated for teaching in textbook-limited and teacher-centered method may have hard time for successful implementation of the project work. Further, he added that there are various emerging trends and issues in ELT and even though we are master or Ph.D. degree holders, we are not very aware of such things. The author agrees with him in a sense that theoretical knowledge is not enough for practical application of the PBL and which is lacking in most of the teachers in Nepalese context. Actually, 21st century teachers need to 
be a constructivist teacher who can create the learning environment for the learners, where learners can independently consult and explore the wide resources and construct the knowledge on their own. However, this is what is lacking here.

Regarding this issue, Tikaram also put his view in the same line of though. He stated that it is also difficult to use it in rural area, because there is difficult to find out professionals to provide the relevant information. Further, he said, "There is also lack of the resources, professionalism in teachers who can create such learning environment.” Another burning challenge in implementation of PBL is the lack of resources, especially in rural areas where it is very hard to find out the resourceful person to make the in-depth study of subject matter. Similarly, it is another bitter reality that most of the teachers lack professionalism, research and technological skills, and study habits. Rather they take this teaching profession as time pass, so that they do not have to be jobless, unless and until they do not get other opportunities. Likewise, Tikaram, regarding this issue, put his view that students have to go to the field and library to collect the data. In-depth study lies in the heart of PBL. Time and again, students have to visit the library, use internet, and field visit for data collection, but the reality is that most of the schools do not have library. And those which have, they are not equipped with the sufficient resources. So, they are maintained just for show. PBL is useful in terms of as Pearlman (2006) said in generating smarter, more creative, and capable manpower by managing, collaborating, and networking with productive people around the world. However, finding the teachers, Sunil, further expresses that it is challenging in our context who can successfully handle the project in teaching learning activities.

Similarly, Surya pointed another genuine challenge in our context that students, most of the students, feel difficult while going through PBL, because they are habituated in traditional kind of classroom teachings. Rameshwor, again in this issue, expressed although there are several teaching training programs held by the Ministry of Education and various private organizations in the different intervals of time, they have not been able to address the current trends and issues.

To sum up, from the above discussion, it is vivid that PBL is an effective approach of teaching and one of the best approaches of teaching, suitable for the 21st learners. It has a big scope in Nepalese context, because it can be an effective tool to revolutionize the traditional educational practices of Nepal. Moreover, it can be an effective tool for producing the smarter and multi-dynamic human resources with both in-depth content knowledge and life skill needed to cope with the 21st global challenges of the uncertain future. However, there are several challenges in its successful implementation. Therefore, it is necessary to address these several challenges proving adequate resources and training to the teachers in current trends and issues.

\section{Implications of the Study}

This research study is made based on the findings and conclusions of the intensive interview of the five research participants who have been directly or indirectly involved with the PBL in their teaching learning pedagogy as an integral part of their classroom teaching. Based on the ideas they have expressed, the author could finally draw the following implications. The author is hopeful that these implications would be helpful for us as well as any EFL teachers as well as other subject teachers for effective teaching learning practices, providing the opportunities for the learners to learn with real life experience outside the classroom engaging them in meaningful learning. Moreover, it can be also useful for those teachers, educators, policy-makers, and teacher training experts who have been exploring the ways to bring out changes in the present teaching learning system. Similarly, it will also help the learning in a different learning environment. 
PBL is a practical, research-based, and effective approach of teaching which provides opportunities for the learners to work in real life situations working in collaboration. There is high level of motivation of the learners for their active and prolonged engagement for in-depth investigation of the topic. Due to their high level of motivation and in-depth investigation, the learning achievement is high. It is an interdisciplinary in nature suitable for the 21st century learners for preparing them for 21st century global context variety of 21st knowledge and skills.

However, there are several challenges for the successful application of PBL in Nepalese context, due to the lack of material resources, skilled and professional human resources, and crowded classrooms. Adequate material resources, trained and skilled human resources, use of information and communication technology (ICT), and spacious classroom are necessary to make the PBL a success. The traditional classroom should be developed as a workplace equipped with necessary equipments for the 21st century learners. The role of teacher must be transformed from authoritarian to facilitator, coordinator, initiator, guide working with the students and students from passive listeners to co-workers, meaning makers, active learner, team builder, and manager, etc..

\section{Conclusion}

This research article deals with PBL which is a very new concept in teaching learning system in the context of Nepal. PBL is a modern, research-based, and practical teaching approach which provides an ample opportunity for the learners to work along with the guidance of the teacher who provides them with necessary scaffolding. So, the role of teacher and student is quite different in comparison of the traditional classroom. Teacher plays the role of facilitator, guider, co-learner, and co-worker manager who creates the learning environment for the learners, whereas the role of students is also to be active learner, meaning maker, and so on. The traditional congested classroom needs to be transformed as a workplace with sufficient space, so that students can perform various activities in collaboration. It has been an effective approach for active and prolonged engagement of the learners with high level of motivation. Although there are several challenges in the successful application of PBL, there are also several opportunities for the learners. Using PBL as an integral part of teaching learning practices, students can develop variety of knowledge and skills needed for the 21st century global context with in-depth information. The successful implementation of PBL is possible, only through managing adequate material resources and teaching learning practices, and managing necessary pre-requisites, the sufficient learning resources, and skilled human resources in Nepalese context.

\section{References}

Ball, B. (2012). A summary of motivation theories. Retrieved from http://www.yourcoach.be/en/employee-motivation-ebook.pdf

Bass, S. (2014). Project-based learning: A short history. Edutopia. Trending: Teach visual literacy with social media (Originally published in Sept. 9, 2011). Retrieved from http://www.edutopia.org/sylvia-chard-project-learning

Brewster, C., \& Fager, J. (2000). Increasing student engagement and motivation: From time-on-task to homework. Publisher: North West Regional Education Laboratory. Retrieved from http://www.nwrel.org/partnerships/pubs/building.html

Broz, B. (1999). A pedagogy of community and collaboration: A beginning in teaching in the 21st century. In A. Robertson \& B. Smith (Eds.), Writing pedagogies to the college curriculum. New York, N.Y.: Falmer Press. Retrieved from http://www.questia.com/read

Chard, S. C. (2014). Project learning (originally written in 2001). Retrieved from http://www.edutopia.org/sylvia-chard-projectlearning

Deffelice, W. (1996). Using story jokes for real communication. English Teaching Forum, 50(2), 43-44.

Grant, M. M. (2002, Winter). Getting a grip on project-based learning: Theory, cases, and recommendations. Meridian: A Middle School Computer Technologies Journal, 5(1). Retrieved from http://www.ncsu.edu/meridian/win2002/514 
Highet, G. (2008). The art of teaching. Surgeet Publications, New Delhi, India.

ICAL, Quality Teacher Training (2014). Classroom focus. Retrieved from http://www.icaltefl.com

Janet, G. (2006). Constructivism: A holistic approach to teaching and learning. Retrieved from http://www.niu.edu/facdev/_pdf/ constructivism.pdf

Karn, S. K. (2007). Current trends in ELT around the globe. Journal of Nepal English Language Teachers’ Association (NELTA), $12(1 \& 2), 60-66$.

Lucas, G. (2003). Learning in action! The George Lucas Educational Foundation [PowerPoint slides]. Retrieved from http://www.edutopia.org

Meganathan, R. (2011). Project work to promote English language learning. New Delhi, India: Teach English.

Pearlman, B. (2006). 21st century learning in schools-A case study of new technology high school in Napa, CA. In E. Schwarz \& K. Kay (Eds.), New Directions for Youth Development. Retrieved from http://www.bobpearlman.org/Articles/21stCentury Learning.htm

Pearlman, B. (2009). Making 21st century schools: Creating learner-centered school place/workplaces for a new culture of students at work. Educational Technology. Retrieved from http://www.bobpearlman.org/Articles/21stCenturyLearning.htm

Pearlman, B. (2010). Teaching and learning in the 21st century school district [PowerPoint slides]. Retrieved from http://www.bobpearlman.org/Learning21/index.htm

Shanks, N. H. (2007). Management and motivation (Chapter 2). Jpnes and Bartlett Publisher.

Smith, B. (1999). Role playing in the interdisciplinary classroom. In A. Robertson \& B. Smith (Eds.), Teaching in the 21st century: Adapting writing pedagogies to the college curriculum. New York, N.Y.: Falmer Press. Retrieved from www.questia.com/read

Stripling, B., Lovett, N., \& Macko, F. L. (2000). Project-based learning: Inspiring middle school students to engage in deep and active learning (Edit in 2009). Publisher: NYC, Department of Education, 52 Chambers Streets, New York.

Toshalis, E., \& Nakkula, M. J. (2012). Motivation, engagement, and student voice. Students at the center series: Teaching and learning in the area of common core, job for the future project. Retrieved from http:// www.jff.org.pdf 